\title{
INVESTIGATING THE RELATIONSHIP BETWEEN SERUM PENTRAXIN3 LEVEL AND ANGIOGRAPHIC FINDINGS IN PATIENTS WITH CORONARY ANGIOGRAPHY
}

\author{
HABIB HEYBAR ${ }^{1}$, AHMADREZA ASSAREH ${ }^{1}$, SOMMAYEH JALALI ${ }^{2 *}$ \\ ${ }^{1}$ Cardiovascular Research Center, Ahvaz Jundishapur University of Medical Science, Ahvaz, Iran. ${ }^{2}$ Department of Cardiology, Ahvaz \\ Jundishapur University of Medical Science, Ahvaz, Iran. Email: sommayeh.jalali@gmail.com
}

Received: 10 October 2017, Revised and Accepted: 22 January 2018

\section{ABSTRACT}

Objective: Pentraxin3 (PTX3) is an inflammatory single-phase mononuclear polysorbate glycoprotein, synthesized by endothelial, macrophages, and mildew cells; based on reports and research findings, it is also believed to be synthesized in the tissue of atherosclerotic lesions of arterial arteries. Therefore, PTX3 can be considered as a more specific marker for atherosclerosis. The present study examines the relationship between PTX3 serum levels and coronary angiography findings.

Methods: A total of 100 patients with stable cardiac status under elective coronary angiography were studied. Meanwhile, serum levels of PTX3 were measured, along with coronary angiography, in these patients. Finally, the relationship between the serum level of this marker and the severity of the angiographic findings of these individuals was compared and contrasted.

Results: out of 100 patients examined in the present study, 57 subjects (57.6\%) were male and 42 subjects (42.4\%) were female. The mean age of

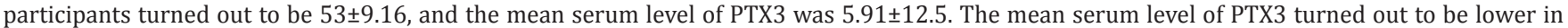
patients with normal angiography than in those with coronary artery disease $(\mathrm{p}<0.0001)$. Smoking and age did not affect the mean serum levels of this marker. Furthermore, a higher serum level of PTX3 was associated with a higher syntax score in the angiography $(\mathrm{p}<0.0001)$.

Conclusion: Serum levels of PTX3 can have a predictive value in the diagnosis of coronary artery disease in patients with stable cardiovascular symptoms.

Keywords: Pentraxin, Coronary angiography, Syntax score.

(c) 2018 The Authors. Published by Innovare Academic Sciences Pvt Ltd. This is an open access article under the CC BY license (http://creativecommons. org/licenses/by/4. 0/) DOI: http://dx.doi.org/10.22159/ajpcr.2018.v11i3.23011

\section{INTRODUCTION}

Coronary artery disease is currently the most common cause of death in most parts of the world, both developed and developing countries, including Iran; it accounts for $40 \%$ of all deaths in these countries [1,2].

Inflammatory processes play a key role in the emergence and development of atherosclerosis [3]. Atherosclerosis or hardness of the arteries is the name of a type of disease in the veins, which is characterized by the deposition of lipids and other substances in the internal wall tissue of some arteries. The result of this process is the formation of fibrous-lipid plaques (atroma), which develops with increasing age, leading to stenosis and inflammation and, finally, coronary artery disease [4]. Pentraxin3 (PTX3) is an inflammatory single-phase mononuclear polysorbate glycoprotein, synthesized by endothelial, macrophages, and mildew cells [5]. PTX3 is released from platelet-induced neutrophils in the coronary artery bypass (CAD) graft [6], and acts through inflammatory processes in the CAD; it, even, acts as a prognostic factor for CAD admission [7]. Interestingly, the production of PTX3 in the tissue of atherosclerotic lesions of arterial arteries has also been reported [8]. Some studies have associated high levels of PTX3 with unstable angina [9] and adverse outcomes following myocardial infarction [10]. Compared with high-sensitivity C reactive protein (HsCRP) protein, PTX3 has been shown to be more specific in vascular inflammation and has been associated with the progression of atherosclerosis and vascular disease independently [11]. However, the precise role of PTX3 in the pathogenesis of cardiovascular disease requires further exploration [12].

Inflammation plays an important role in each stage of the onset and progression of atherosclerosis. Therefore, many studies have already been conducted to find an inflammatory marker as predictive and prognostic of coronary artery disease. The most prominent inflammatory marker that has ever been studied is CRP. The accumulation of CRP in atherosclerotic plaques has been proven. There is also a positive direct correlation between serum CRP and cardiovascular risk. CRP, which is a member of PTX series, as a nonspecific marker, has a pentameric structure and is synthesized in the liver in response to inflammatory processes and is a non-specific marker [12,13].

PTX3 was initially identified as an inflammatory marker initiating inflammatory response; however, since it was later on identified specifically as an inflammatory marker in response to vascular injury, it became a reliable indicator in the prediction of the possibility of obstruction and vascular damage.

Many studies have, so far, been done on the role of PTX3 in acute coronary and myocardial infarction and its comparison among stable and unstable patients. In addition, other studies which have been conducted on patients with stable heart conditions, the level of PTX3 in the majority of cases was administered locally and during invasive angiographic procedures, such as the femoral artery.

It seems that serum level can be used as a marker to predict coronary artery involvement in patients undergoing elective coronary angiography. Since there is no comprehensive study conducted on stable patients on this issue in this epidemiological area, the present study was conducted to find a relationship between serum PTX3 level and coronary angiography findings in subjects undergoing elective angiography. 


\section{METHODS}

A total of 100 patients referred to educational centers of Golestan and Imam Khomeini Hospitals of Ahvaz, with stable cardiac status were considered candidate based on initial examination, exercise tests, myocardial perfusion scan, and cardiologist diagnosis of elective angiography; these subjects were categorized into three groups of one, two, and three vessels on the basis of the number of vessels involved. Demographic information of patients, including age, sex, and medications, was collected through a questionnaire. PTX3 serum level was determined in Pardis campus according to enzyme-linked immunosorbent assay (ELISA) method. Furthermore, the patient's syntax score was calculated by the software and recorded in the questionnaire.

Considering the potential for interference with the level of PTX3, the main exclusion criteria included the presence of glucose metabolism disorder such as diabetes mellitus impaired fasting glucose, impaired glucose tolerance, heart failure (EF $<50 \%$ ), and kidney failure (GFR $<60$ ). The serum level of PTX3 was measured along with coronary angiography in these subjects. PTX was measured and examined through ELISA method and CUSABIO BIOTECH CO, Ltd., Japan kit; finally, the relationship between average serum level of this marker and the severity of angiographic findings was determined based on the presence or absence of coronary involvement, the number of vessels involved and the severity of the conflict according to SYNTAX score.

\section{Statistical analysis}

Quantitative variables are used to illustrate descriptive results. The qualitative variables are presented as percentages. For analytical analysis, ANOVA tests were used to compare the serum level of PTX3 in three groups; additionally, Chi-square and independent $t$ tests were used to compare the results of three groups.

\section{Ethical considerations}

1. The researcher introduced himself for the volunteers, explained the objective of the research, assured them about the confidentiality of the information, and obtained their written consent.

2. All forms used for collecting information form patients are anonymous.

3. Participation in research for all eligible patients is entirely optional and free.

4. Patients are not charged for injected serums, and the research was conducted entirely free.

\section{Findings}

Out of 100 patients examined in the present study, 57 subjects (57.6\%) were male and 42 subjects (42.4\%) were female. The mean age of participants turned out to be $53 \pm 9.16$, and the mean serum level of PTX3 was 5.91 \pm 12.5 . The qualitative results of the study included mean age, sex percentages of patients, mean PTX3 serum level, and syntax score of patients, all of which are indicated in following Tables 1-6 and graphs.

The mean PTX3 serum level difference was $1.18 \pm 2.4$ between two sexes, which showed a significant difference between the two sexes in terms of serum level of this marker ( $p$ value $=0.042$ ).

According to the findings of the present study, the mean syntax score difference turned out to be $13.6140 \pm 1.38$ among male and $1.32 \pm 8.2857$ among female subjects.

One-way ANOVA test was used to examine the difference between the levels of PTX3 in different stages of vessel involvement, the results of which are shown in the following table; as you can see, there was a significant difference in serum levels of PTX3, compared to other groups, at least in the groups with normal coronary angiography $(p<0.0001)$. There was also a significant difference between three and two vessels groups in the level of PTX3 in the coronary angiography $(\mathrm{p}=0.037)$.

In addition, the relationship between syntax score difference and the number of involved vessels turned out to be significant, meaning that, at least in two groups, there is a significant difference between the score of the patients' syntax and the number of vessels involved.

In fact, the results showed that the syntax score of groups with normal angiography and minimal CAD was significantly lower than three blood vessels groups.

\section{DISCUSSION}

The present study suggests that serum levels of PTX3 can be a valuable marker for differentiating patients with normal coronary angiography from those with coronary involvement. However, this study provided no differentiation between patients with coronary involvement on the basis of the number of involved vessels or PTX3 rate. It has been shown that the serum level of PTX3 in patients with three vessels is significantly higher than those with double-vessel involvement. It was,

Table 1: The relationship between smoking and the number of vascular involvement in angiography

\begin{tabular}{|c|c|c|c|c|c|c|}
\hline \multicolumn{7}{|c|}{ Smoking *number of vessels cross tabulation } \\
\hline \multirow[t]{2}{*}{ Smoking status } & \multicolumn{5}{|c|}{ The number of vessels } & \multirow[t]{2}{*}{ Total } \\
\hline & Normal (\%) & Minimal (\%) & One vessel & Two vessels & Three vessels & \\
\hline \multirow{2}{*}{\multicolumn{7}{|c|}{$\begin{array}{l}\text { Smoking } \\
\text { Smoking }\end{array}$}} \\
\hline & & & & & & \\
\hline Count ${ }^{\circ}$ & 10 & 3 & 9 & 5 & 6 & 33 \\
\hline$\%$ within smoking & 30.3 & 9.1 & 27.3 & 15.2 & 18.2 & 100.0 \\
\hline $\begin{array}{l}\% \text { within number of } \\
\text { vessels }\end{array}$ & 30.3 & 15.8 & 42.9 & 41.7 & 42.9 & 33.3 \\
\hline$\%$ of total & 10.1 & 3.0 & 9.1 & 5.1 & 6.1 & 33.3 \\
\hline \multicolumn{7}{|l|}{ No smoking } \\
\hline Count & 23 & 16 & 12 & 7 & 8 & 66 \\
\hline$\%$ within smoking & 34.8 & 24.2 & 18.2 & 10.6 & 12.1 & 100.0 \\
\hline $\begin{array}{l}\% \text { within number of } \\
\text { vessels }\end{array}$ & 69.7 & 84.2 & 57.1 & 58.3 & 57.1 & 66.7 \\
\hline$\%$ of total & 23.2 & 16.2 & 12.1 & 7.1 & 8.1 & 66.7 \\
\hline \multicolumn{7}{|l|}{ Total } \\
\hline Count & 33 & 19 & 21 & 12 & 14 & 99 \\
\hline$\%$ within smoking & 33.3 & 19.2 & 21.2 & 12.1 & 14.1 & 100.0 \\
\hline $\begin{array}{l}\% \text { within number of } \\
\text { vessels }\end{array}$ & 100.0 & 100.0 & 100.0 & 100.0 & 100.0 & 100.0 \\
\hline$\%$ of Total & 33.3 & 19.2 & 21.2 & 12.1 & 14.1 & 100.0 \\
\hline
\end{tabular}


Table 2: The mean serum levels of pneumotoxic based on patients' gender

\begin{tabular}{|c|c|c|c|c|c|c|c|c|c|}
\hline \multicolumn{10}{|c|}{ Independent samples test } \\
\hline \multirow[t]{3}{*}{ Variable } & \multicolumn{2}{|c|}{$\begin{array}{l}\text { Levene's test for } \\
\text { equality of variances }\end{array}$} & \multicolumn{7}{|c|}{ T-test for equality of means } \\
\hline & \multirow[t]{2}{*}{$\mathbf{F}$} & \multirow[t]{2}{*}{ Significant } & \multirow[t]{2}{*}{$\mathbf{t}$} & \multirow[t]{2}{*}{ df } & \multirow[t]{2}{*}{ p value } & \multirow[t]{2}{*}{ Mean difference } & \multirow[t]{2}{*}{$\begin{array}{l}\text { Standard error } \\
\text { difference }\end{array}$} & \multicolumn{2}{|c|}{$\begin{array}{l}95 \% \text { confidence interval of } \\
\text { the difference }\end{array}$} \\
\hline & & & & & & & & Lower & Upper \\
\hline
\end{tabular}

Table 3: The relationship between serum levels of PTX3 and the number of involved vessels

\begin{tabular}{|c|c|c|c|c|c|c|}
\hline \multirow[t]{2}{*}{ (I) number of vessels } & \multirow[t]{2}{*}{ (J) number of vessels } & \multirow[t]{2}{*}{ Mean difference (I-J) } & \multirow[t]{2}{*}{ Standard error } & \multirow[t]{2}{*}{ Significant } & \multicolumn{2}{|c|}{$95 \%$ confidence interval } \\
\hline & & & & & $\begin{array}{l}\text { Lower } \\
\text { bound }\end{array}$ & $\begin{array}{l}\text { Upper } \\
\text { bound }\end{array}$ \\
\hline \multirow[t]{4}{*}{ Normal } & Minimal & $-6.62203^{*}$ & 1.31574 & 0.000 & -10.2817 & -2.9624 \\
\hline & One vessel & $-6.95892 *$ & 1.27536 & 0.000 & -10.5062 & -3.4116 \\
\hline & Two vessels & $-5.78023^{*}$ & 1.54014 & 0.003 & -10.0640 & -1.4964 \\
\hline & Three vessels & $-10.98368^{*}$ & 1.45724 & 0.000 & -15.0369 & -6.9305 \\
\hline \multirow[t]{4}{*}{ Minimal } & Normal & $6.62203^{*}$ & 1.31574 & 0.000 & 2.9624 & 10.2817 \\
\hline & One vessel & -0.33689 & 1.44659 & 0.999 & -4.3605 & 3.6867 \\
\hline & Two vessels & 0.84180 & 1.68467 & 0.987 & -3.8440 & 5.5276 \\
\hline & Three vessels & -4.36165 & 1.60923 & 0.060 & -8.8376 & 0.1143 \\
\hline \multirow[t]{4}{*}{ One vessel } & Normal & $6.95892 *$ & 1.27536 & 0.000 & 3.4116 & 10.5062 \\
\hline & Minimal & 0.33689 & 1.44659 & 0.999 & -3.6867 & 4.3605 \\
\hline & Two vessels & 1.17869 & 1.65333 & 0.953 & -3.4199 & 5.7773 \\
\hline & Three vessels & -4.02476 & 1.57638 & 0.088 & -8.4094 & 0.3599 \\
\hline \multirow[t]{3}{*}{ Two vessels } & Normal & $5.78023 *$ & 1.54014 & 0.003 & 1.4964 & 10.0640 \\
\hline & Minimal & -0.84180 & 1.68467 & 0.987 & -5.5276 & 3.8440 \\
\hline & Three vessels & $-5.20345^{*}$ & 1.79735 & 0.037 & -10.2027 & -0.2042 \\
\hline \multirow[t]{4}{*}{ Three vessels } & Normal & $10.98368 *$ & 1.45724 & 0.000 & 6.9305 & 15.0369 \\
\hline & Minimal & 4.36165 & 1.60923 & 0.060 & -0.1143 & 8.8376 \\
\hline & One vessel & 4.02476 & 1.57638 & 0.088 & -0.3599 & 8.4094 \\
\hline & Two vessels & $5.20345^{*}$ & 1.79735 & 0.037 & 0.2042 & 10.2027 \\
\hline
\end{tabular}

*The mean difference is significant at the 0.05 level

Table 4: The relationship between the score of syntax and the number of vessels involved in angiography

\begin{tabular}{|c|c|c|c|c|c|c|}
\hline \multicolumn{7}{|l|}{ Multiple comparisons } \\
\hline \multicolumn{7}{|c|}{ Dependent variable: Syntax score } \\
\hline \multicolumn{7}{|l|}{ Tukey HSD } \\
\hline \multirow[t]{2}{*}{ (I) number of vessels } & \multirow[t]{2}{*}{ (J) number of vessels } & \multirow[t]{2}{*}{ Mean difference (I-J) } & \multirow[t]{2}{*}{ Standard error } & \multirow[t]{2}{*}{ Significant } & \multicolumn{2}{|c|}{$95 \%$ confidence interval } \\
\hline & & & & & Lower bound & Upper bound \\
\hline \multirow[t]{4}{*}{ Normal } & Minimal & $-15.00000^{*}$ & 1.66526 & 0.000 & -19.6318 & -10.3682 \\
\hline & One vessel & $-17.19048^{*}$ & 1.61415 & 0.000 & -21.6801 & -12.7008 \\
\hline & Two vessels & $-15.41667^{*}$ & 1.94927 & 0.000 & -20.8384 & -9.9949 \\
\hline & Three vessels & $-20.92857^{*}$ & 1.84434 & 0.000 & -26.0585 & -15.7986 \\
\hline \multirow[t]{4}{*}{ Minimal } & Normal & $15.00000^{*}$ & 1.66526 & 0.000 & 10.3682 & 19.6318 \\
\hline & One vessel & -2.19048 & 1.83087 & 0.753 & -7.2829 & 2.9020 \\
\hline & Two vessels & -0.41667 & 2.13220 & 1.000 & -6.3472 & 5.5139 \\
\hline & Three vessels & $-5.92857^{*}$ & 2.03671 & 0.036 & -11.5936 & -0.2636 \\
\hline \multirow[t]{3}{*}{ One vessel } & Normal & $17.19048^{*}$ & 1.61415 & 0.000 & 12.7008 & 21.6801 \\
\hline & Minimal & 2.19048 & 1.83087 & 0.753 & -2.9020 & 7.2829 \\
\hline & Three vessels & -3.73810 & 1.99514 & 0.339 & -9.2875 & 1.8113 \\
\hline \multirow[t]{4}{*}{ Two vessels } & Normal & $15.41667^{*}$ & 1.94927 & 0.000 & 9.9949 & 20.8384 \\
\hline & Minimal & 0.41667 & 2.13220 & 1.000 & -5.5139 & 6.3472 \\
\hline & One vessel & -1.77381 & 2.09253 & 0.915 & -7.5940 & 4.0464 \\
\hline & Three vessels & -5.51190 & 2.27481 & 0.118 & -11.8392 & 0.8153 \\
\hline \multirow[t]{4}{*}{ Three vessels } & Normal & $20.92857^{*}$ & 1.84434 & 0.000 & 15.7986 & 26.0585 \\
\hline & Minimal & $5.92857^{*}$ & 2.03671 & 0.036 & 0.2636 & 11.5936 \\
\hline & One vessel & 3.73810 & 1.99514 & 0.339 & -1.8113 & 9.2875 \\
\hline & Two vessels & 5.51190 & 2.27481 & 0.118 & -0.8153 & 11.8392 \\
\hline
\end{tabular}

${ }^{*}$ The mean difference is significant at the 0.05 level. According to the results of the present study, there is, also, a significant relationship between syntax score and PTX3 serum level of the patients $(\mathrm{p}<0.05 ; \mathrm{r}=0.89)$ 
also, found that mean serum level of PTX3 in patients with significant vascular involvement was considerably higher among males. However, there was no relationship between smoking and the serum level of this marker.

Polat Nerkiz et al. showed that PTX3 is a useful pre-angiography predictor of vascular involvement [14]. According to results of this study, increase in the number of involved vessels caused the level of this serum to higher, which did not turn out to be consistent with the findings of the present study, according to which PTX3 serum level was significantly lower in two groups with normal angiography, in comparison to other groups. In addition, the level of this marker in patients with two blood vessels involved was considerably higher than those with three vessels involved.

Based on the results of Liu Haibo et al. study, which was conducted in 2014 under the title of "Evaluating PTX3 as a predictive marker of post-vascular metastatic events after the implementation of the DES stent," high level of this marker is highly efficient in predicting possible major cardiovascular events only hours after the instalment of the DES stent [15]. The present study differed from this study in several ways. First, only patients who were candidates for PCI were evaluated in this study and this marker was not considered in patients with stable cardiac status. However, according to the results of the present study, PTX3 can be used as a marker for treating patients with vascular disorder even without intervention or the necessity of implementing PCI.

A study conducted by Marie Tomandlova et al. in 2015 found that high levels of serum PTX3 can predict 1-year mortality of patients with STEMI; these patients are more likely to be afflicted with ventricular dysfunction after MI, causing their mortality to go higher and higher after 1 year [16]. However, both the nature and examined population of the present study differed hugely with their study.

Table 5: The relationship between PTX3 serum level and syntax score

\begin{tabular}{lll}
\hline Correlations & & \\
\hline PTX3 & PTX3 & Syntax score \\
\hline Pearson correlation & 1 & $0.898^{* *}$ \\
Significant (two-tailed) & & 000 \\
N & 99 & 99 \\
Syntax score & & \\
Pearson correlation & $0.898^{* *}$ & 1 \\
Significant (two-tailed) & 0.000 & \\
N & 99 & 99 \\
\hline
\end{tabular}

Statistical analysis showed that syntax score and serum level of PTX3 did not

differ significantly between smokers and non-smokers $(p=0.6,0.4)$
Marie's study examined the prognostic impact of PTX3 in regard to cardiovascular events; but, the present study looked at the predictive role and diagnostic value of this marker. In addition, while their study examined only patients with unstable cardiovascular status, ours was specifically conducted on those with stable cardiac conditions. A simple comparison of the findings of these two studies indicates that carrying out further research will provide immeasurable help in determining and introducing PTX3 as a predictive and prognostic marker for both stable and unstable patients with heart problems.

In a cross-sectional study conducted on patients with STEMI in 2016 by Alipour-Parsa et al., following results were obtained. Patients with higher serum levels of PTX3 experienced more serious involvement in coronary angiography than the other groups; they were in more urgent need of PCI and intervention, in comparison to those with normal serum level; patients with higher level of PTX3 had lower EF, higher GRACE scores, and higher grade Killip class in comparison with those with normal PTX3 level [17]. Our study also found that people with higher PTX3 had higher syntax score, which means that, in addition to the prognostic value of this marker in cardiovascular complications, it is possible that even the severity of coronary artery disease and the probability of need for PCI can be predicted. This study determined serum levels of $0.29 \mathrm{ng} / \mathrm{dl}$ and above as a cut point predictor of highintensity coronary involvement. However, the present study focused merely on the numerical relationship between the level of this marker and the prediction of coronary involvement and the threshold and the cutoff point were not specified for the probable differentiation of healthy patients from patients with coronary involvement $[18,19]$.

With regard to the above findings, carrying out further research will provide immeasurable help in determining and introducing PTX3 as a predictive and prognostic marker for both stable and unstable patients with heart problems.

However, the results of the present study indicated that a low level of serum PTX3 has a predictive value for, at least, predicting normal coronary artery and no significant involvement. Actually, this marker seems to be more specific rather than sensitive in diagnosing and predicting critical coronary artery disease. Perhaps in the future, this marker can be used to reject coronary artery disease in patients with low to moderate risk, with atypical symptoms or those who have noninvasive results in non-diagnostic cases.

However, the present study had, also, some weaknesses. First, this study was conducted on patients with the stable cardiovascular disease, and it cannot be claimed whether PTX3 serum would have the same prognostic value for patients with a critical cardiovascular condition or not. However, some studies conducted on unstable patients have shown that this marker not only has no prognostic value, it might actually

Table 6: The relationship between PTX3 serum level and syntax score with smoking

Independent samples test

\begin{tabular}{|c|c|c|c|c|c|c|c|c|c|}
\hline & \multicolumn{2}{|c|}{$\begin{array}{l}\text { Levene's } \\
\text { equality of variances }\end{array}$} & \multicolumn{7}{|c|}{ T-tesstfor equality of mefons } \\
\hline & \multirow[t]{2}{*}{$\mathbf{F}$} & \multirow[t]{2}{*}{ Significant } & \multirow[t]{2}{*}{$\mathbf{t}$} & \multirow[t]{2}{*}{ Df } & \multirow[t]{2}{*}{$\mathrm{p}$ value } & \multirow[t]{2}{*}{$\begin{array}{l}\text { Mean } \\
\text { difference }\end{array}$} & \multirow[t]{2}{*}{$\begin{array}{l}\text { Standard } \\
\text { error } \\
\text { difference }\end{array}$} & \multicolumn{2}{|c|}{$\begin{array}{l}95 \% \text { confidence } \\
\text { interval of the } \\
\text { difference }\end{array}$} \\
\hline & & & & & & & & Lower & Upper \\
\hline \multicolumn{10}{|l|}{ PTX3 } \\
\hline Equal variances assumed & 1.933 & 0.168 & -0.837 & 97 & 0.405 & -1.05636 & 1.26256 & -3.56220 & 1.44947 \\
\hline $\begin{array}{l}\text { Equal variances not } \\
\text { assumed }\end{array}$ & & & -0.938 & 86.168 & 0.351 & -1.05636 & 1.12580 & -3.29431 & 1.18158 \\
\hline \multicolumn{10}{|l|}{ Syntax score } \\
\hline Equal variances assumed & 1.397 & 0.240 & -0.501 & 97 & 0.617 & -1.07576 & 2.14528 & -5.33355 & 3.18203 \\
\hline $\begin{array}{lll}\text { Equal variances } & \text { not } \\
\text { assumed } & & \end{array}$ & & & -0.537 & 76.911 & 0.593 & -1.07576 & 2.00379 & -5.06590 & 2.91438 \\
\hline
\end{tabular}


exacerbate their critical condition and necessitate the implementation of PCI in these patients.

Another weakness of our study was that a cut-off point and a specific number could not be determined to predict coronary artery disease or a small probability of coronary involvement, and it would not be possible to identify a certain level PTX3 that could reject coronary disorder with absolute certainty.

One of the strengths of the present study is that the necessity of coronary angiography was initially determined by non-invasive methods and medical examinations, increasing the specificity of PTX3 serum level in rejection of coronary artery disease. Another strength of the present study is simultaneous study of other factors, such as age, sex, smoking, and the severity of vascular involvement, based on the diameter of the lumen, apart from the examination of the number of vessels involved, and their relationship with PTX3 level, which had not been done in former researches.

\section{CONCLUSION}

PTX3 serum levels can be predictive of coronary heart disease in patients with the stable cardiovascular condition. In addition, the serum level of this marker is lower in patients with normal angiography, in comparison to those with coronary artery diseases. Serum level of this marker is, also, higher in males and patients with significant traceability. However, smoking and age had no effect on the mean serum levels of this marker in the present study.

\section{CONFLICTS OF INTEREST}

All authors have none to declare

\section{REFERENCES}

1. Murray CJ, Lopez AD. Global mortality, disability, and the contribution of risk factors: Global burden of disease study. Lancet 1997;349:1436-2.

2. World Health Organization. World Health Report 1999 Making a Difference. Geneva: World Health Organization; 1999. Available from: http://www.who.int/whr/1999/en whr99_en. [Last accessed on 2014 Jun 25].

3. Liuzzo G. Atherosclerosis: An inflammatory disease. Rays 2001;26:221-30

4. Maseri A, Fuster V. Is there a vulnerable plaque? Circulation 2003;107:2068-71.

5. Garlanda C, Bottazzi B, Bastone A, Mantovani A. Pentraxins at the crossroads between innate immunity, inflammation, matrix deposition, and female fertility. Annu Rev Immunol 2005;23:337-66.

6. Maugeri N, Rovere-Querini P, Slavich M, Coppi G, Doni A, Bottazzi B, et al. Early and transient release of leukocyte pentraxin 3 during acute myocardial infarction. J Immunol 2011;187:970-9.

7. Reid PC, Ito Y, Miyauchi K, Mantovani A. Pentraxin and female fertility. Ann Rev Immunol 2005;23:337-66.

8. Savchenko A, Imamura M, Ohashi R, Jiang S, Kawasaki T, Hasegawa G, et al. Expression of pentraxin 3 (PTX3) in human atherosclerotic lesions. J Pathol 2008:215:48-55.

9. Inoue K, Sugiyama A, Reid PC, Ito Y, Miyauchi K, Mukai S, et al. Establishment of a high sensitivity plasma assay for human pentraxin3 as a marker for unstable angina pectoris. Arterioscler Thromb Vasc Biol 2007;27:161-7.

10. Latini R, Maggioni AP, Peri G, Gonzini L, Lucci D, Mocarelli P, et al. Prognostic significance of the long pentraxin PTX3 in acute myocardial infarction. Circulation 2004;110:2349-54

11. Knoflach M, Kiechl S, Mantovani A, Cuccovillo I, Bottazzi B, Xu Q, et al. Pentraxin-3 as a marker of advanced atherosclerosis results from the bruneck, ARMY and ARFY studies. PLoS One 2012;7:e31474.

12. Doganer YC, Aydogan U, Aydogdu A, Parci M, Akbulut H, Nerkiz P, et al. Relationship of Cystatin $\mathrm{C}$ with coronary artery disease and severity. Coron Artery Dis 2013;24:119-26.

13. George SJ, Lyon J. Pathogenesis of atherosclerosis. In: George SJ, Johnson J, editors. Atherosclerosis: Molecular and Cellular Mechanisms. Weinheim: Wiley-VCH; 2010. p. 3-14.

14. Nerkiz P, Doganer YC, Aydogan U, Akbulut H, Parlak A, Aydogdu A, et al. Serum pentraxin-3 level in patients who underwent coronary angiography and relationship with coronary atherosclerosis. Med Princ Pract 2015;24:369-75

15. Haibo L, Xiaofang G, Chunming W, Jie Y, Guozhong C, Limei Z, et al. Prognostic value of plasma pentraxin-3 levels in patients with stable coronary artery disease after drug-eluting stent implantation. Mediators Inflamm 2014;2014:963096.

16. Tomandlova M, Jarkovsky J, Tomandl J, Kubkova L, Kala P, Littnerova S, et al. Prognostic value of pentraxin-3 level in patients with STEMI and its relationship with heart failure and markers of oxidative stress. Dis Markers 2015;2015:159051.

17. Alipour-Parsa S, Haybar H, Namazi MH, Safi M, Khaheshi I, Memaryan M, et al. Evaluation of pentraxin-3 level and its related factors in patients undergoing primary percutaneous coronary intervention. ARYA Atheroscler 2017;13:73-8.

18. Mirvete R, Mirela M, Ela P, Ledjan M. Comparison of reteplase doublebolus administration with streptokinase in acute myocardial infarction. Int J Pharm Pharm Sci 2015;7:180-3.

19. Gavishiddappa AH, Ishwar BB, Balappa MB, Shardha BR. Study on variations in the branching pattern of arch of aorta. Int J Pharm Pharm Sci 2015;7:515-7. 